\title{
Tenascin-C Modulates Adhesion of Cardiomyocytes to Extracellular Matrix during Tissue Remodeling after Myocardial Infarction
}

\author{
Kyoko Imanaka-Yoshida, Michiaki Hiroe, Toshio Nishikawa, Shigeru Ishiyama, \\ Takashi Shimojo, Yoshiko Ohta, Teruyo Sakakura, and Toshimichi Yoshida
}

Department of Pathology (KI-Y, TSa, TY), Mie University School of Medicine, Mie; Second Department of Medicine (MH, TS), Tokyo Medical and Dental University, Tokyo; and Department of Pathology (TN, SI, YO), Tokyo Women's Medical University, Tokyo, Japan

\begin{abstract}
SUMMARY: Tenascin-C (TNC), an extracellular matrix glycoprotein, plays important roles in tissue remodeling. TNC is not normally expressed in adults but reappears under pathologic conditions. The present study was designed to clarify the contribution of TNC to ventricular remodeling after myocardial infarction. We examined the expression of TNC after experimental myocardial infarction in the rat by immunohistochemistry and in situ hybridization. Within 24 hours of permanent coronary ligation, interstitial fibroblasts in the border zone started to express TNC mRNA. The expression of TNC was down-regulated on Day 7 and was no longer apparent by Day 14 after infarction. During the healing process, TNC protein and TNC-producing cells were found at the edges of the residual myocardium. Some of the TNC-producing cells were immunoreactive for $\alpha$-smooth muscle actin. In culture, TNC increased the number of cardiomyocytes attached to laminin but inhibited the formation of focal contacts at costameres. The results indicate that during the acute phase after myocardial infarction, interstitial cells in the border zone synthesize TNC, which may loosen the strong adhesion of surviving cardiomyocytes to connective tissue and thereby facilitate tissue reorganization. (Lab Invest 2001, 81:1015-1024).
\end{abstract}

$T$ enascins constitute a family of extracellular matrix glycoproteins (Erickson, 1993). The first member found, tenascin-C (TNC), is highly expressed in embryonic tissue during morphogenesis and sparsely expressed in the adult, but reappears during wound healing, regeneration, or cancer invasion (Chiquet-Ehrismann et al, 1986). TNC is transiently expressed in distinct areas in association with active tissue remodeling. Various in vitro findings have indicated that TNC has multiple functions in the regulation of cell migration, proliferation, and apoptosis (Chung et al, 1996; Jones and Jones, 2000). TNC counterbalances cell adhesion to substrata, correlated with cytokinesis and motility, and prevents cells from adhering too tightly to other extracellular matrix proteins (Chiquet-Ehrismann, 1995; Chiquet-Ehrismann et al, 1988; Chung et al, 1996; Murphy-Ullrich et al, 1991; Prieto et al, 1992).

In the heart, TNC appears only at very early stages of embryonic development and may play important roles in the differentiation of cardiomyocytes, struc-

Received April 3, 2001.

This research was supported by a Mie Medical Research Foundation grant-in-aid (1998), and by grants-in-aid from the Ministry of Education, Science Sports and Culture of Japan to KI-Y.

Address reprint requests to: Dr. Kyoko Imanaka-Yoshida, Department of Pathology, Mie University School of Medicine, 2-174 Edobashi, Tsu, Mie 514-8507, Japan.E-mail:imanaka@doc.medic.mie-u.ac.jp tural organization of the myocardium, or development of coronary vessels (Imanaka-Yoshida et al, 2000). TNC is not normally expressed in the adult heart but reappears under various pathologic conditions such as dilated cardiomyopathy, myocarditis, or myocardial infarction (Imanaka-Yoshida et al, 1998, 2000; Tamura et al, 1996; Willems et al, 1996).

To understand its roles in tissue remodeling in the diseased myocardium, we examined the expression of TNC during tissue repair after experimental myocardial infarction in rats. Sequential changes in the localization of the molecule were analyzed by immunohistochemistry, and TNC-producing cells were identified by in situ hybridization (ISH) combined with immunohistochemistry. Additionally, to study the biologic functions of TNC in cardiomyocytes, we isolated the cells from an adult rat heart and examined the effects of addition of exogenous TNC on cell attachment. Cardiomyocytes have a special cell-extracellular matrix attachment system, the costamere (reviewed in Imanaka-Yoshida, 2000), which was originally described as a striated distribution of vinculin colocalized with the Z-lines of myofibrils (Craig and Pardo, 1983; Pardo et al, 1983). Costameric attachment prevents slippage of cardiomyocytes during contraction and transmits contraction forces from myofibrils to surrounding connective tissue (Danowski et al, 1992; ImanakaYoshida et al, 1996, 1999). In culture, costameric attachment can be identified as a characteristic 
banded distribution of focal contacts by interference reflection microscopy (IRM) (Danowski et al, 1992; Imanaka-Yoshida et al, 1996, 1999). We investigated the effects of TNC on this adhesion.

Our results suggest that during the acute phase after myocardial infarction interstitial cells in the border zone synthesize TNC, which may loosen strong adhesion to connective tissue to help in the rearrangement of surviving cardiomyocytes.

\section{Results \\ Localization and Expression of TNC Protein and mRNA after Myocardial Infarction}

Twenty-four hours after coronary ligation, positive interstitial TNC immunoreactivity was found in the border zone between infarcted and intact areas (Fig. 1a). TNC mRNA was observed in interstitial cells but not in cardiomyocytes (Fig. 1b). Neither immunoreac-
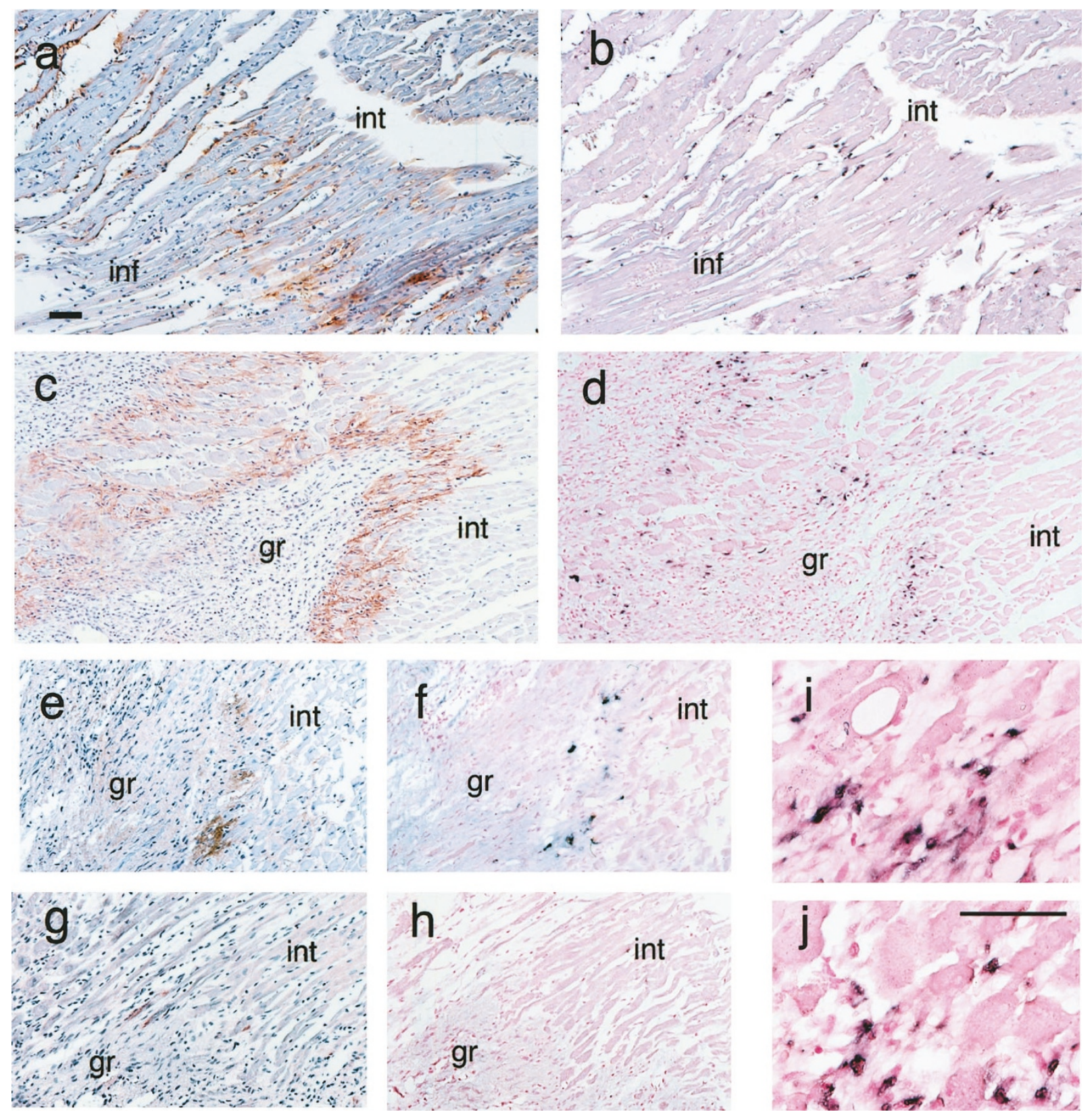

Figure 1.

Immunoreactivity (a, c, e, and g) for tenascin-C (TNC) and in situ hybridization (ISH) for TNC mRNA (b, d, f, h, and i) and the TNC alternative splicing region (j) in rat myocardial tissue sections 24 hours (a and b), 5 days (c, d, i, and j), 7 days (e and f), and 14 days ( $g$ and h) after coronary ligation. Deposition of TNC protein and mRNA for TNC is apparent in the border zone between infarcted (inf) and intact (int) areas within 24 hours (a and b). On Day 5, immunoreactivity and mRNA for TNC are localized in the border zone between the intact (int) myocardium and granulation tissue $(g r)(\mathrm{c}$ and d). Enlarged images of serial sections of a border zone (i and j). Interstitial cells express TNC mRNA (i) with alternative splicing sites (j). Protein and mRNA levels are low at Day 7 (e and f) and are almost lacking by Day 14 ( $\mathrm{g}$ and $\mathrm{h}$ ). Bars: a, $50 \mu \mathrm{m}$ for panels a to $\mathrm{h} ; \mathrm{j}, 50 \mu \mathrm{m}$ for panels $\mathrm{i}$ and $\mathrm{j}$. 
tivity nor mRNA was detected within the infarcted area or in the remote areas.

Approximately 3 days after infarction, the necrotic myocardium began to be replaced by granulation tissue. Deposits of TNC-immunoreactive and TNC mRNA-positive cells were observed in the marginal zone (Fig. 1, c and d) and at developing fronts of granulation tissue around necrotic cardiomyocytes (Fig. 2, f and g). No TNC immunoreactivity or mRNA was detected in the granulation tissue itself (Fig. 1, c and d). Around Day 7 after infarction, both the expression of TNC mRNA and the level of TNC protein in the border zone seemed to be down-regulated (Fig. 1, e and f), and they had almost disappeared by Day 14 (Fig. 1, g and h). No discrepancy between mRNA and protein levels was evident. The duration of expression of TNC in the infarcted areas depended on the size of the infarct. The expression continued as long as the necrotic masses remained.

Assessment of the expressed isoforms of TNC by a cRNA probe for the alternative splicing region of fibronectin type III-like repeats of TNC (see "Materials and Methods") revealed that cells expressed the larger isoform, which contains the alternative splicing sites (Fig. 1, i and j).

\section{Characterization of TNC-Expressing Cells}

Signals for TNC mRNA were detected only in interstitial cells, not in cardiomyocytes (Fig. 1, b, d, f, i, and j, and Fig. 2b). However, not all interstitial cells were positive for TNC mRNA. To characterize the TNCproducing cells, we examined the distribution of myofibroblasts using antibodies to $\alpha$-smooth muscle actin (SMA). After 24 hours, although TNC mRNA-positive interstitial cells and deposition of TNC molecules were detected (Fig. 2, a and b), only vascular cells were immunoreactive for SMA (Fig. 2a). Other SMAimmunoreactive cells started to appear around Day 3, consistent with a previous report (Vracho and Thorning, 1991). Double immunoreactivity for TNC and SMA in the same tissue section showed that SMAimmunoreactive cells appeared in the area where TNC immunoreactivity was present (Fig. 2, c and d).

However, double-labeling for SMA and TNC mRNA in the same tissue section showed that most TNCproducing cells were negative for SMA, and most SMA-immunoreactive cells were negative for TNC mRNA at this stage (Fig. 2e). At Day 5, TNCsynthesizing cells were localized at the border zone and at the periphery of the necrotic masses (Fig. 2g) where TNC molecules were deposited (Fig. 2f). In contrast, SMA-immunoreactive cells were distributed over a broader area within granulation tissue (Fig. 2, f and h). Careful comparison of serial sections (Fig. 2, i and j) showed that some cells expressing TNC mRNA were also immunoreactive for SMA, which indicated that some myofibroblasts were expressing TNC.

\section{Western Blotting}

By Western blot analysis, two isoforms of TNC, of approximately 230 and $220 \mathrm{kd}$, were identified in Day
7 culture medium (Fig. 3). On Day 3, a faint band for the larger isoform was detected. No bands were detected on Day 0 , the day the cells were plated.

\section{Immunofluorescence}

Cardiomyocytes plated on laminin-coated coverglasses gradually spread, and reorganized myofibrils with regular striation of I-bands by Day 7 (Fig. 4a). In the same culture, contaminating fibroblasts started to proliferate at approximately Day 3. After treating the cells with monensin to prevent intracellular vesicular transport, immunofluorescent reactivity for TNC revealed accumulation of TNC-positive granules in the perinuclear region of fibroblasts but not in cardiomyocytes (Fig. 4b), which confirmed the observations obtained by ISH in the tissue sections.

\section{Adhesion Assay}

Cardiomyocytes attached to the coverglasses maintained their original rod shape and the striated structure of myofibrils at 24 hours after plating (Fig. 5b). With IRM, approximately 60 percent of cardiomyocytes attached to laminin showed a characteristic striated distribution of dark contact, whose periodicity resembled that of Z-lines of myofibrils (Fig. 5b), which we refer to as costameric attachment, as previously reported (Imanaka-Yoshida et al, 1996). The other cells did not show costameric attachment but attached to the substratum with gray or white contacts (Fig. 5b). The total number of attached cells was higher on the mixture of laminin and TNC than on laminin alone. Addition of TNC to laminin significantly reduced the adhesion at costameric attachments on laminin, but promoted noncostameric attachment. Addition of fibronectin did not affect the number of the cells, regardless of whether there was costameric attachment (Fig. 5a).

\section{Discussion}

\section{TNC Appears Transiently in the Acute Phase after Myocardial Infarction}

Our present study demonstrated that both TNC mRNA and TNC protein deposition appear in the border zone as early as 24 hours after coronary ligation and that they are both down-regulated approximately 7 days after infarction. Such transient up-regulation of TNC is consistent with the previous immunohistochemical findings for human infarcted myocardium (Willems et al, 1996). Early expression of TNC is also reported after various tissue injuries, and is related to cell migration or proliferation (Fassler et al, 1996; ImanakaYoshida et al, 2001; Latijnhowwers et al, 1996; Whitby and Ferguson, 1991; Yoshimura et al, 1999).

\section{TNC Inhibits Stable Adhesion, but Supports the Transient Attachment of Cardiomyocytes}

The most striking feature of TNC expression after myocardial infarction is that its distribution is restricted to the border zone. This limited distribution 

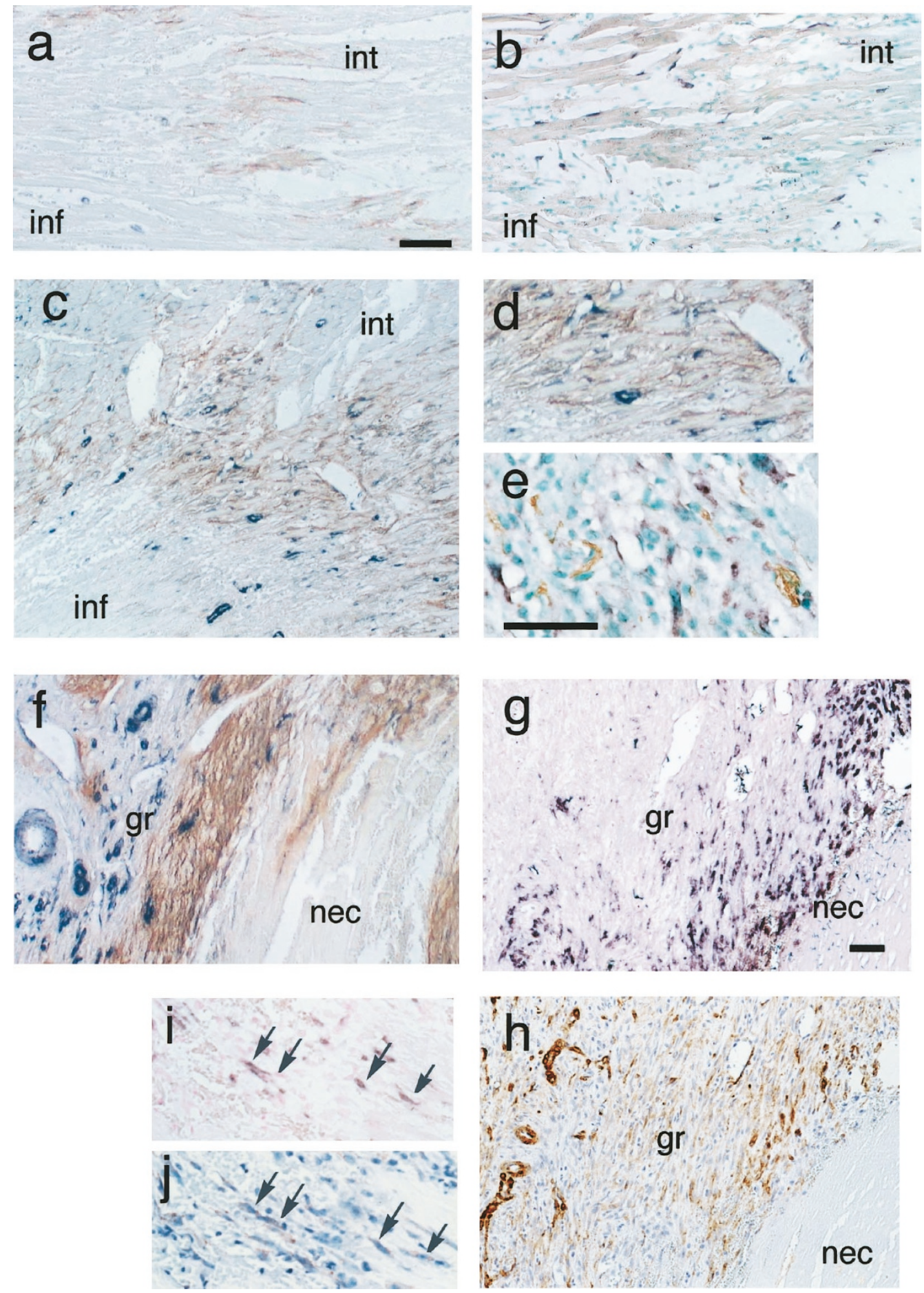

Figure 2.

The distribution of $\alpha$-smooth muscle actin (SMA)-immunoreactive cells, TNC molecule, and TNC-expressing cells at Day 1 (a and b), Day 3 (c, d, and e), and Day 5 ( $f, g$, and h). ISH for TNC (b, g, and i), immunoreactivity for SMA (h), double labeling for immunoreactivity of SMA and ISH for TNC mRNA (e), double immunoreactivity for TNC and SMA in the same tissue section (a, c, d, and f). At Day 1 (a), deposition of TNC can be detected (brown), but only vascular cells are immunoreactive for SMA (blue), although several interstitial cells express TNC mRNA (b). At Day 3 (c), SMA-immunoreactive interstitial cells (blue) appear in the TNC-immunoreactive area (brown) at the border zone. d, High-power view of c. Double labeling for SMA immunoreactivity and TNC mRNA (e) shows that most TNC-producing cells (purple) are negative for SMA (brown) and most SMA-immunoreactive cells are also not expressing TNC. At Day 5, TNC immunoreactivity (brown in $\mathrm{f}$ ) and cells positive for TNC mRNA ( $\mathrm{g}$ ) are seen at the periphery of the necrotic mass in the granulation tissue. Some SMA-immunoreactive cells (blue in f) are seen in the TNC-positive area but distributed over a broader area (brown in h; compare with g). High-power view of ISH for TNC (i) and immunoreactivity for SMA (j) of serial sections shows that the same cells are positive for both SMA and TNC signals (arrows). Bars: a, $50 \mu \mathrm{m}$ for panels b and c; e, $50 \mu \mathrm{m}$ for panels d, e, $\mathrm{i}$, and j; g, $50 \mu \mathrm{m}$ for panels f, g, and h). Abbreviations: inf, infarcted area; int, intact area; nec, necrotic mass; gr, granulation tissue. 


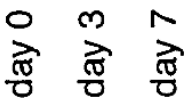

$207 \mathrm{kd}-^{-}+$

$121 \mathrm{kd}-$

$81 \mathrm{kd}-$

Figure 3.

Western blot analysis of culture medium of adult rat cardiomyocytes with fibroblasts on Days 0,3 , and 7 . Two isoforms of TNC are evident at approximately $220 \mathrm{kd}$ and $230 \mathrm{kd}$ on Day 7 . A faint band at $230 \mathrm{kd}$ is seen on Day 3. No bands are evident on Day 0.
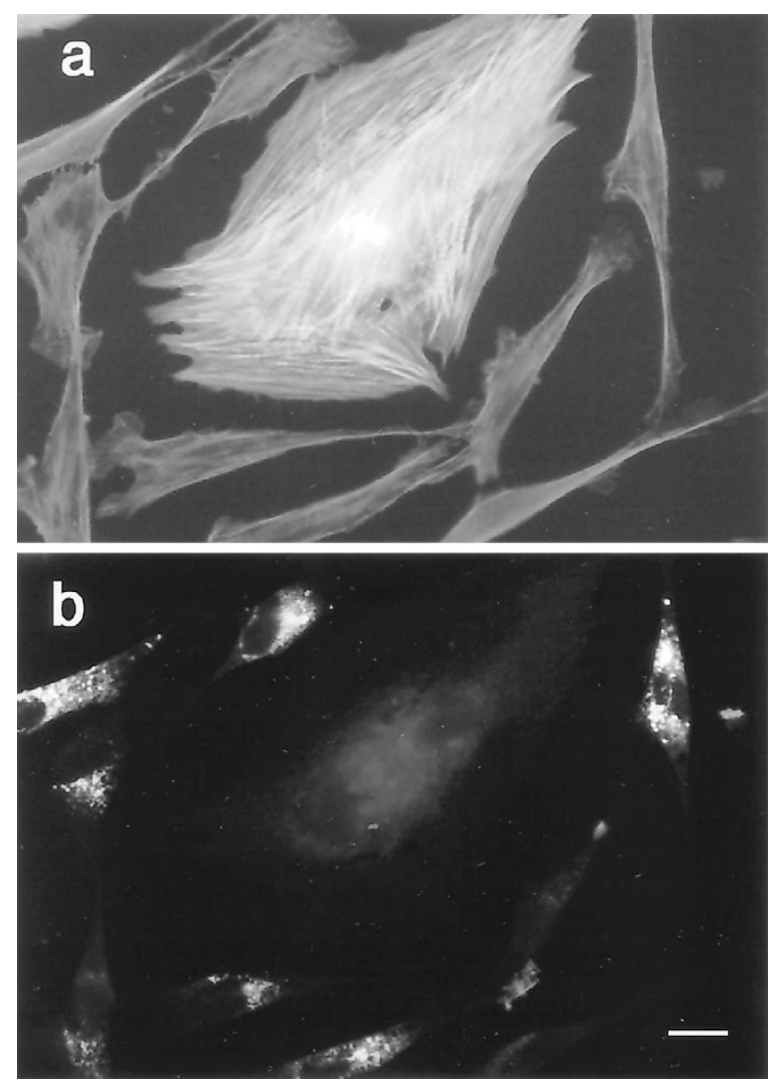

Figure 4.

Adult rat cardiomyocytes cultured for 7 days, doubly stained for rhodaminephalloidin (a) and anti-TNC (b), 2 hours after monensin treatment. A cardiomyocyte showing striated myofibrils and fibroblasts with nonstriated stress fibers is present in the same culture. Numerous TNC-immunoreactive granules are evident in the perinuclear region only in fibroblasts. Bar: $10 \mu \mathrm{m}$. suggests special roles of TNC at the edges of the residual myocardium during tissue remodeling after infarction.

In normal myocardium, cardiomyocytes are not only joined together at intercalated disks but also firmly anchored to connective tissue with costamere complexes containing vinculin, talin, integrin $\alpha 6 \beta 1$, and laminin (Danowski et al, 1992; Imanaka-Yoshida, 2000; Imanaka-Yoshida et al, 1996, 1999). Costameric adhesion prevents cardiomyocytes from slipping during contraction, and transmits the contraction force of myofibrils to interstitial collagen fibrils surrounding individual myocytes, allowing the normal heart to function as a single pump (Danowski et al, 1992; Imanaka-Yoshida et al, 1999). However, during tissue remodeling after myocardial infarction, the surviving cardiomyocytes at the border zone need to loosen this attachment to reorganize the cell shape or arrangement.

In fact, although adult rat cardiomyocytes can form costameric focal contacts upon plating on laminin (Imanaka-Yoshida et al, 1996, 1999), the cells transiently lose these strong attachments during the changing of cell shape and reorganization of the cytoskeleton to adapt to the new environment in culture (Imanaka-Yoshida et al, 1996, 1999; LoRusso et al, 1992). Instead, cells maintain their adherence to substrates via noncostameric white or gray contacts during the extensive remodeling (Imanaka-Yoshida et al, 1996). When cytoskeletal reorganization is completed, costameric attachment is regained and becomes strong enough to link myofibrils to the substratum and transmit contraction forces (Danowski et al, 1992; Imanaka-Yoshida et al, 1996, 1999).

As we showed in this study, TNC inhibits cardiomyocytes from forming costameric focal contacts but increases the number of cells with noncostameric attachment. TNC is generally thought to be a counteradhesion molecule, but its effects on cell adhesion are complex. Several lines of evidence indicate that TNC has both adhesive and counter-adhesive domains, and that its binding to cells is mediated by various receptors (Fischer et al, 1997a, 1997b; Gotz et al, 1996; Prieto et al, 1992, 1993). Thus, TNC can inhibit adhesion (Chiquet-Ehrismann et al, 1988; Lightner and Erickson, 1990) or support weak and transient attachment (Lotz et al, 1989) depending on the cell type. TNC may mediate de-adhesion by shifting cells from strong adhesion to temporary attachment (Greenwood and Murphy-Ullrich, 1998). As we found here, TNC may inhibit strong adhesion at costameres but promote temporary noncostameric attachment of cardiomyocytes. This de-adhesion effect would be helpful for dynamic tissue remodeling at the edges of residual myocardium. Furthermore, TNC has the ability to induce production of matrix metalloproteinase (MMP) in certain types of cells (Tremble et al, 1994). The degradation of connective tissue should also put the cells into an adaptable state for active tissue reorganization. These alterations would be useful for an early adaptive reaction but might also cause cell slippage, 


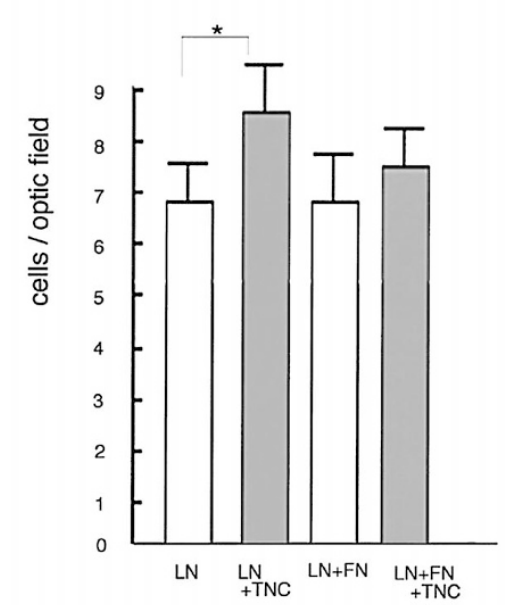

costameric attachment (+)

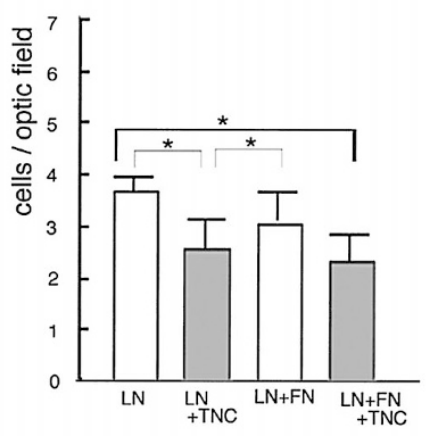

costameric attachment (-)

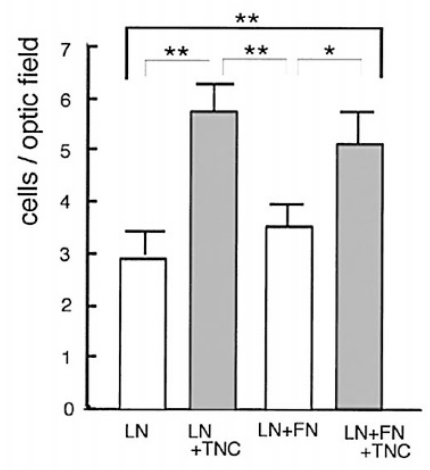

b
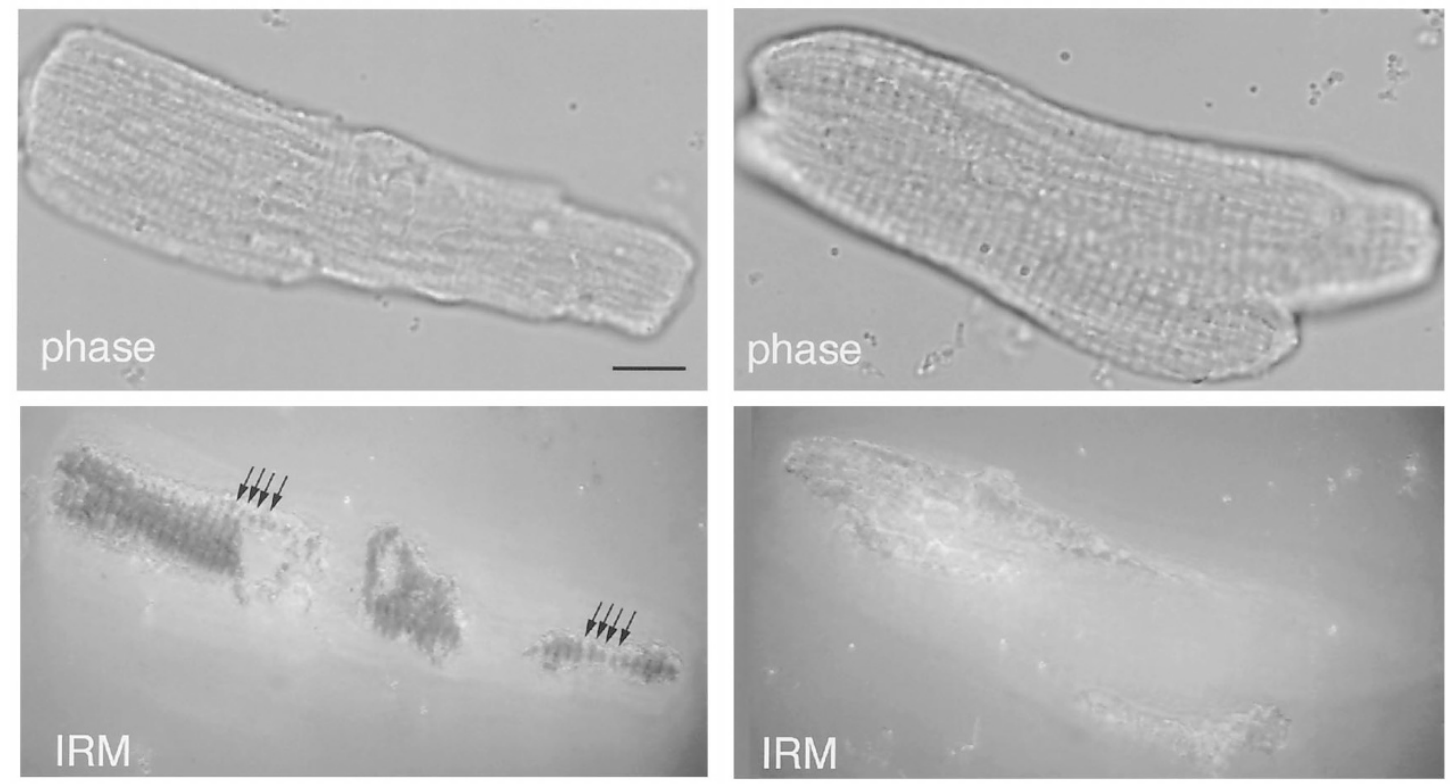

costameric attachment (+)

costameric attachment (-)

Figure 5.

The effects of TNC on cardiomyocyte attachment (a). Adult rat cardiomyocytes were plated on cover glasses coated with laminin (LN), TNC plus laminin (LN + TNC), fibronectin plus laminin (LN+FN), or TNC plus fibronectin and laminin (LN+FN+TNC). The total number of attached cells and costameric attachment-positive and -negative cells within 10 fields per cover glass were counted and averaged. Error bars represent the standard deviation for triplicate samples. The number of costameric attachment-positive cells on TNC plus laminin was significantly lower than the numbers on laminin or laminin plus fibronectin. Asterisks denote significant differences ( ${ }^{\star} p<0.05$ or ${ }^{* *} p<0.01$ ) according to Students' $t$ test. Similar results were obtained in three separate experiments. b, Interference reflection microscopy (IRM) and phase-contrast photomicrographs of cardiomyocytes after 24 hours of incubation. The cells are rod shaped and maintain their original myofibrils under phase contrast microscopy. The attachment pattern observed by IRM was classified into two groups: costameric adhesion, showing striated dark contacts whose periodicity resembled that of Z-lines of myofibrils (arrows), and noncostameric adhesion, with gray and white contacts.

leading to ventricular dilatation after myocardial infarction. In fact, side-to-side slippage of cardiomyocytes is greater in the border zone (Anversa et al, 1993).

\section{Are Myofibroblasts a Major Source of TNC?}

During cancer invasion (Hanamura et al, 1997; Yoshida et al, 1997) or embryonic development of mammary glands (Kalembey et al, 1997), both mesenchymal and epithelial/parenchymal cells synthesize TNC. In contrast, our present study showed that TNC production after myocardial infarction was limited to interstitial cells. Injured cardiomyocytes may send signals to neighboring fibroblasts to synthesize TNC, which regulates myocyte adhesion in a paracrine fashion.

In cancer stroma, myofibroblasts are a major cellular source of TNC (Hanamura et al, 1997). Myofibroblasts 
share characteristics with both fibroblasts and smooth muscle cells expressing proteins such as SMA (Desmouliere and Gabbiani, 1994), and appear in various tissues during wound healing or cancer stroma. In normal tissue, repertories of myofibroblasts such as pericryptal cells of the colonic mucosa or stellate cells of the liver synthesize TNC (Hanamura et al, 1997; Murakami et al, 1995).

As we demonstrated in the present study, some myofibroblasts contribute to production of TNC in myocardial scar tissue. However, on Day 1 after infarction, TNC-producing cells were negative for SMA. SMA-immunoreactive cells appeared at approximately Day 3, in the area where the TNC molecules were deposited. TNC might be related to the differentiation of interstitial resident fibroblasts into myofibroblasts or to the activation of the locomotion of myofibroblasts. In the heart, myofibroblasts are thought to provide the contractile force to prevent ventricular dilatation after infarction ( $\mathrm{Li}$ et al, 1999; Vracho and Thorning, 1991; Vracko et al, 1989; Willems et al, 1994). TNC may not only modulate cardiomyocyteextracellular matrix attachment, but may also play multiple roles in myocardial tissue remodeling to control interstitial cell behavior during repair of tissue damage.

\section{Materials and Methods}

\section{Antibodies and Reagents}

TNC was purified from the culture supernatant of U251 MG human glioma cells, as previously described (Yoshida et al, 1999). Laminin (EHS tumor derived) and human fibronectin were purchased from GIBCO BRL (Gaithersburg, Maryland). Rabbit polyclonal antibodies to TNC were raised against human melanoma TNC (Hasegawa et al, 1997). Peroxidase-conjugated antiSMA (EPOS) was obtained from Dako Japan (Kyoto, Japan).

\section{Myocardial Infarction Model}

Adult male Wistar rats weighing 250 to $300 \mathrm{~g}$ were used. The animals were anesthetized with pentobarbital (60 mg/kg ip) and ventilated by positive pressure through endotracheal tubes attached to a Harvard small animal respirator. The left descending coronary artery was ligated. At different times (1, 3, 5, 7, 14, and 21 days) after surgery, a total of 18 rats ( $n=3$ for each group) were anesthetized with pentobarbital (60 $\mathrm{mg} / \mathrm{kg} \mathrm{ip)} \mathrm{and} \mathrm{their} \mathrm{hearts} \mathrm{were} \mathrm{removed} \mathrm{and} \mathrm{fixed}$ overnight in $4 \%$ paraformaldehyde in $0.1 \mathrm{M}$ sodium

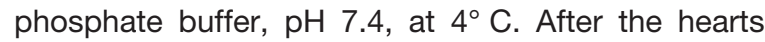
were rinsed in the same buffer, they were dehydrated through a graded ethanol series and xylene, embedded in paraffin, sectioned at 4- $\mu \mathrm{m}$ thick, and placed on silane-coated slide glasses (Dako Japan).

\section{Immunohistochemistry}

For TNC immunoreactivity, the sections were equilibrated in distilled water, and incubated in $0.4 \%$ pepsin (1:60,000; Sigma Chemical Corporation, St. Louis, Missouri) in $0.01 \mathrm{~N} \mathrm{HCl}$ for 10 minutes at $37^{\circ} \mathrm{C}$ to retrieve the antigens. The sections were then exposed to $0.3 \% \mathrm{H}_{2} \mathrm{O}_{2}$ in methanol for 15 minutes to block endogenous peroxidase activity, and treated with superblock solution (ScyTek Laboratories, Logan, Utah) before incubation with primary antibodies $(1 \mu \mathrm{g} / \mathrm{ml})$ overnight at $4^{\circ} \mathrm{C}$. After extensive washing, the sections were incubated with peroxidase-conjugated anti-rabbit IgG (1:500; MBL, Nagoya, Japan) for 1 hour. After the sections were washed, a diaminobenzidine and $\mathrm{H}_{2} \mathrm{O}_{2}$ solution was used to demonstrate antibody binding. For anti-SMA, a prediluted solution was used. For double immunohistochemistry for TNC and SMA, the sections were first processed for TNC immunoreactivity. After the first coloring reaction, the slides were fixed with $4 \%$ paraformaldehyde in PBS for 30 minutes, exposed to $0.3 \% \mathrm{H}_{2} \mathrm{O}_{2}$ in methanol for 15 minutes, treated with superblock solution, and incubated with peroxidase-conjugated anti-SMA. To detect the second signal, a diaminobenzidine and $\mathrm{NiCl}_{2}$ solution was used. Therefore, the TNC immunoreactivity was brown in color, whereas the SMA immunoreactivity was blue. For double-labeling with SMA immunoreactivity and ISH for TNC, the sections were first processed for SMA immunoreactivity, labeled with ISH, then lightly counterstained with methylgreen solution.

\section{Preparation of cRNA Probes}

Antisense and sense cRNA probes were prepared by in vitro transcription of mouse TNC cDNA (95\% homology with rat) (Saga et al, 1991) using a digoxigenin RNA-labeling kit (SP6/T7; Boehringer Mannheim, Mannheim, Germany), as previously reported (Tsukamoto et al, 1991). We used two types of cRNA probes to examine TNC isoforms. The 6th through 11th fibronectin type III-like repeats (A1, A2, A4, B, C, and D) of mouse TNC are alternatively spliced sites. TNC mRNA including these sequences generates TNC isoforms of large molecular weight. In the present study, a probe derived from the cDNA encoding these repeats, designated FNAE by Tsukamoto et al (Tsukamoto et al, 1991), was used alone to detect large isoforms. Probes for other regions were used as a mixture to detect mRNAs for all isoforms of TNC.

\section{ISH}

The preparation of tissue sections, ISH method, and color development were as previously described by Ishihara et al (1995). The processing included treatment with protease $\mathrm{K}$ for 20 minutes. The slides were lightly counterstained with nuclear fast red or methylgreen solution. 


\section{Cell Culture}

Adult rat cardiomyocytes were isolated from the hearts of male Wistar rats (200 to $250 \mathrm{~g}$ ) by retrograde perfusion with collagenase, as previously described (Imanaka-Yoshida et al, 1993; LoRusso et al, 1992), suspended in DMEM supplemented with $10 \%$ fetal calf serum and plated on coverglasses coated with laminin (GIBCO BRL).

\section{Western Blotting}

Proteins secreted by mixed cultures of cardiomyocytes and fibroblasts were analyzed by immunoblotting, as previously described (Hasegawa et al, 1997; Kalembey et al, 1997). On Days 0, 3, and 7, supernatants of culture medium ( $15 \mu \mathrm{l} /$ lane) were subjected to SDS-PAGE with $2 \%$ to $15 \%$ gradient polyacrylamide gels and transferred by electrophoresis onto Immobilon membranes (Millipore, Bedford, Massachusetts). The transferred proteins were immunoreacted with the TNC antibody $(2.5 \mu \mathrm{g} / \mathrm{ml})$ using the indirect immunoperoxidase method. After several washes, the membranes were incubated with peroxidase-conjugated goat anti-rabbit IgG ( $\mathrm{H}+\mathrm{L}$-chain specific, 500-fold diluted; $M B L)$, and immunoreactivity was detected with the ECL system (Amersham, Arlington Heights, Illinois).

\section{Adhesion Assay}

Coverglasses were coated overnight at $4^{\circ} \mathrm{C}$ with either laminin dissolved in PBS at a concentration of $20 \mu \mathrm{g} / \mathrm{ml}$, or a mixture of laminin $(20 \mu \mathrm{g} / \mathrm{ml})$ and fibronectin $(20 \mu \mathrm{g} / \mathrm{ml})$. After rinsing with PBS, some coverglasses were incubated with TNC $(40 \mu \mathrm{g} / \mathrm{ml})$ for at least 1 hour. Coated coverglasses were blocked with $2 \mathrm{mg} / \mathrm{ml}$ of BSA in PBS for 30 minutes.

Freshly isolated cardiomyocytes were suspended in DME containing $10 \%$ fetal bovine serum. The cell suspension was adjusted to a final concentration of 2 $\times 10^{4}$ cells $/ \mathrm{ml}$, and $2 \mathrm{ml}$ aliquots were plated on coverglasses $(24 \times 18 \mathrm{~mm})$ coated with various substrates in 35-mm tissue culture dishes and incubated at $37^{\circ} \mathrm{C}$ for 24 hours. Unattached cells were removed by washing the plates with DMEM. Cells on the coverglasses were fixed with $4 \%$ paraformaldehyde in PBS for 15 minutes and mounted with $50 \%$ glycerol in PBS.

The total number of attached cells was counted in random fields observed under phase optics with a $40 \times$ objective. Attachment was confirmed by IRM, as previously described (Imanaka-Yoshida et al, 1999). With IRM, black areas of images indicate distances between the ventral surface and the substratum of approximately 10 to $15 \mathrm{~nm}$, whereas gray areas indicate separation of approximately $30 \mathrm{~nm}$. Light or white areas indicate distances of $100 \mathrm{~nm}$ or more (Izzard and Lochner, 1980). Cardiomyocytes can form a regularly striated distribution of dark contacts, corresponding to Z-lines, when they are plated on laminin (Imanaka-Yoshida et al, 1996). The attachment sites of each cardiomyocyte were enlarged with a $60 \times$ objec- tive to determine whether they had a striated distribution of dark contacts. Within each experiment $(n=3)$, the cells within 10 fields per coverglass were counted and averaged.

\section{Immunofluorescence of Cultured Cells}

For immunofluorescent reactivity, the cells were treated with $1 \mu \mathrm{M}$ monensin for 2 hours to allow accumulation of secretory proteins in the cytoplasm. After fixation in $4 \%$ paraformaldehyde in $0.1 \mathrm{M}$ phosphate buffer (PB) for 15 minutes, the cells were permeabilized with $0.1 \%$ Triton $\mathrm{X}-100$, incubated with $10 \%$ normal goat serum for 30 minutes, and incubated with rabbit anti-TNC antibody $(10 \mu \mathrm{g} / \mathrm{ml})$ overnight at $4^{\circ} \mathrm{C}$. After the cells were washed with PBS, they were incubated with goat FITC-labeled anti-rabbit IgG antibody (MBL) and rhodamine-phalloidin (Molecular Probes, Eugene, Oregon) for 1 hour at room temperature.

\section{Acknowledgement}

We thank S. Naota for her technical assistance.

\section{References}

Anversa P, Olivetti G, Meggs LG, Sonnenblick EH, and Capasso JM (1993). Cardiac anatomy and ventricular loading after myocardial infarction. Circulation 87(Suppl VII):22-27.

Chiquet-Ehrismann R (1995). Inhibition of cell adhesion by anti-adhesive molecules. Curr Opin Cell Biol 7:715-719.

Chiquet-Ehrismann R, Kalla P, Pearson CA, Beck K, and Chiquet $M$ (1988). Tenascin interferes with fibronectin action. Cell 53:383-390.

Chiquet-Ehrismann R, Mackie EJ, Pearson CA, and Sakakura T (1986). Tenascin: An extracellular matrix protein involved in tissue interactions during fetal development and oncogenesis. Cell 47:131-139.

Chung CY, Murphy-Ullrich JE, and Erickson HP (1996). Mitogenesis, cell migration, and loss of focal adhesions induced by tenascin- $C$ interacting with its cell surface receptor, annexin II. Mol Biol Cell 7:883-892.

Craig SW and Pardo JV (1983). Gamma actin, spectrin, and intermediate filament proteins colocalize with vinculin at costameres, myofibril-to-sarcolemma attachment sites. Cell Motil 3:449-462.

Danowski BA, Imanaka-Yoshida K, Sanger JM, and Sanger JW (1992). Costameres are sites of force transmission to the substratum in adult rat cardiomyocytes. J Cell Biol 118:14111420.

Desmouliere A and Gabbiani G (1994). Modulation of fibroblastic cytoskeletal features during pathological situations: The role of extracellular matrix and cytokines. Cell Motil Cytoskel 29:195-203.

Erickson HP (1993). Tenascin-C, tenascin-R and tenascin-X: A family of talented proteins in search of functions. Curr Opin Cell Biol 5:869-876.

Fassler R, Sasaki T, Timple R, Chu ML, and Werner S (1996). Differential regulation of fibulin, tenascin-C, and nidogen expression during wound healing and glucocorticoid-treated mice. Exp Cell Res 222:111-116. 
Fischer D, Brown-Ludi M, Schulthess T, and ChiquetEhrismann R (1997). Concerted action of tenascin-C domains in cell adhesion, anti-adhesion and promotion of neurite outgrowth. J Cell Sci 110:1513-1522.

Fischer D, Tucker RP, Chiquet-Ehrismann R, and Adams JC (1997). Cell-adhesive responses to tenascin-C splice variants involve formation of fascin microspikes. Mol Biol Cell 8:20552075.

Gotz B, Scholze A, Clement A, Joester A, Schutte K, Wigger F, Frank R, Spiess E, Ekblom P, and Faissner A (1996). Tenascin- $C$ contains distinct adhesive, anti-adhesive, and neurite outgrowth promoting sites for neurons. J Cell Biol 132:681-699.

Greenwood JA and Murphy-Ullrich JE (1998). Signaling of de-adhesion in cellular regulation and motility. Microsc Res Tech 43:420-432.

Hanamura N, Yoshida T, Matsumoto E, Kawarada Y, and Sakakura T (1997). Expression of fibronectin and tenascin-C mRNA by myofibroblasts, vascular cells and epithelial cells in human colon adenomas and carcinomas. Int $\mathrm{J}$ Cancer 73: 10-15.

Hasegawa K, Yoshida T, Matsumoto K, Katsuta K, Waga S, and Sakakura T (1997). Differential expression of tenascin-C and tenascin- $X$ in human astrocytomas. Acta Neuropathol 93:431-437.

Imanaka-Yoshida K (2000). The transmission of contractility through cell adhesion. Prog Mol Subcell Biol 25:21-35.

Imanaka-Yoshida K, Danowski BA, Sanger JM, and Sanger JW (1996). Living adult rat cardiomyocytes in culture: Evidence for dissociation of costameric distribution of vinculin from costameric distributions of attachments. Cell Motil Cytoskel 33:263-275.

Imanaka-Yoshida K, Enomoto-Iwamoto K, Yoshida T, and Sakakura T (1999). Contraction force of cardiomyocytes is transmitted to the extracellular matrix through an attachment complex composed of vinculin, talin, integrin $\alpha 6 \beta 1$ and laminin. Cell Motil Cytoskel 42:1-11.

Imanaka-Yoshida K, Ishiyama S, Toyozaki T, Nishikawa T, Yoshida T, Sakakura T, and Hiroe M (1998). Tenascin-C is expressed in myocardium during active stage of myocarditis. J Mol Cell Cardiol 30:A317.

Imanaka-Yoshida K, Matsuura R, Isaka N, Nakano T, Sakakura S, and Yoshida T (In press, 2001). Serial extracellular matrix changes in neointimal lesions of human coronary artery after percutaneous transluminal coronary angioplasty: Clinical significance of early tenascin-C expression. Virchows Arch.

Imanaka-Yoshida K, Sanger JM, and Sanger JW (1993). Contractile protein dynamics of myofibrils in paired adult rat cardiomyocytes. Cell Motil Cytoskel 26:301-312.

Imanaka-Yoshida K, Yokoyama K, and Sakakura T (2000). Possible role of the tenascin family during heart development and myocardial tissue remodeling. In: Takeda N, Nagano M, and Dhalla NS, editors. The hypertrophied heart. Boston: Kluwer Academic Publishers, 123-129.

Ishihara A, Yoshida T, Tamaki H, and Sakakura T (1995). Tenascin expression in cancer cells and stroma of human breast cancer and its prognostic significance. Clin Cancer Res 1:1035-1041.
Izzard CS and Lochner LR (1980). Formation of cell-tosubstrate contacts during fibroblast motility: An interferencereflexion study. J Cell Sci 42:81-116.

Jones FS and Jones PL (2000). The tenascin family of ECM glycoproteins: Structure, function, and regulation during embryonic development and tissue remodeling. Dev Dyn 218: 235-259.

Kalembey I, Yoshida T, Iriyama K, and Sakakura T (1997). Analysis of tenascin mRNA expression in the murine mammary gland from embryogenesis to carcinogenesis: An in situ hybridization study. Int J Dev Biol 41:569-573.

Latijnhowwers MA, Bergers M, van Bergen BH, Spruijt KI, Andriessen MP, and Schalkwijk J (1996). Tenascin expression during wound healing in human skin. J Pathol 178:3035.

Li RK, Jia ZQ, Weisel RD, Merante F, and Mickle DA (1999). Smooth muscle cell transplantation into myocardial scar tissue improves heart function. J Mol Cell Cardiol 31:513522.

Lightner VA and Erickson HP (1990). Binding of hexabrachion (tenascin) to extracellular matrix and its effect on cell adhesion. J Cell Sci 95:263-277.

LoRusso SM, Imanaka-Yoshida K, Shuman H, Sanger JM, and Sanger JW (1992). Incorporation of fluorescently labeled contractile proteins into freshly isolated living adult cardiac myocytes. Cell Motil Cytoskeleton 21:111-122.

Lotz MM, Burdsal CA, Erickson HP, and McClay DR (1989). Cell adhesion to fibronectin and tenascin: Quantitative measurements of initial binding and subsequent strengthening response. J Cell Biol 109:1795-1805.

Murakami K, Abe T, Miyazawa M, Yamaguchi M, Masuda T, Matsuura T, Nagamori S, Takeuchi K, Abe K, and Kyogoku M (1995). Establishment of a new human cell line, LI90, exhibiting characteristics of hepatic Ito (fat-storing) cells. Lab Invest 72:731-739.

Murphy-Ullrich JE, Lightner VA, Aukhil I, Yan YZ, Erickson HP, and Hook M (1991). Focal adhesion integrity is downregulated by the alternatively spliced domain of human tenascin. J Cell Biol 115:1127-1136.

Pardo JV, Siliciano JD, and Craig SW (1983). Vinculin is a component of an extensive network of myofibril-sarcolemma attachment regions in cardiac muscle fibers. J Cell Biol 97:1081-1088.

Prieto AL, Anderson-Fisone C, and Crossin KL (1992). Characterization of multiple adhesive and counteradhesive domains in the extracellular matrix protein cytotactin. J Cell Biol 119:663-678.

Prieto AL, Edelman GM, and Crossin KL (1993). Multiple integrins mediate cell attachment to cytotactin/tenascin. Proc Natl Acad Sci USA 90:10154-10158.

Saga $Y$, Tsukamoto T, Jing N, Kusakabe M, and Sakakura T (1991). Mouse tenascin: cDNA cloning, structure and temporal expression of isoforms. Gene 104:177-185.

Tamura A, Kusachi S, Nogami K, Yamanishi A, Kajikawa Y, Hirohata S, and Tsuji T (1996). Tenascin expression in endomyocardial biopsy specimens in patients with dilated cardiomyopathy: Distribution along margins of fibrotic lesions. Heart 75:291-294. 
Tremble P, Chiquet-Ehrismann R, and Werb Z (1994). The extracellular matrix ligands fibronectin and tenascin collaborate in regulating collagenase gene expression in fibroblasts. Mol Biol Cell 5:439-453.

Tsukamoto T, Kusakabe M, and Saga $Y$ (1991). In situ hybridization with non-radioactive digoxigenin-11-UTPlabeled cRNA probe: Localization of developmentally regulated mouse tenascin mRNAs. Int J Dev Biol 35:25-32.

Vracho $R$ and Thorning D (1991). Contractile cells in rat myocardial scar tissue. Lab Invest 65:214-227.

Vracko R, Thorning D, and Frederickson RG (1989). Connective tissue cells in healing rat myocardium. A study of cell reactions in rhythmically contracting environment. Am J Pathol 134:993-1006.

Whitby D and Ferguson MW (1991). The extracellular matrix of lip wounds in fetal, neonatal and adult mice. Development 112:651-668.

Willems IE, Arends JW, and Daemen MJ (1996). Tenascin and fibronectin expression in healing human myocardial scars. J Pathol 179:321-325.
Willems IE, Havenith MG, De Mey JR, and Daemen MJ (1994). The $\alpha$-smooth muscle actin-positive cells in healing human myocardial scars. Am J Pathol 145:868-875.

Yoshida T, Matsumoto E, Hanamura N, Kalembeyi I, Katsuta K, Ishihara A, and Sakakura T (1997). Co-expression of tenascin and fibronectin in epithelial and stromal cells of benign lesions and ductal carcinomas in the human breast. J Pathol 182:421-428.

Yoshida T, Yoshimura E, Numata H, Sakakura Y, and Sakakura T (1999). Involvement of tenascin-C in proliferation and migration of laryngeal carcinoma cells. Virchows Arch 435:496-500.

Yoshimura E, Majima A, Sakakura Y, Sakakura T, and Yoshida T (1999). Expression of tenascin-C and integrin $\alpha 9$ subunit in regeneration of rat nasal mucosa after chemical injury: Involvement of migration and proliferation of epithelial cells. Histochem Cell Biol 111:259-264. 